\title{
Mujeres tejedoras, diosas guerreras. Mitos de la tradición textil de comunidades zapotecas de la Sierra Sur de Oaxaca
}

\author{
DAMIÁN GONZÁLEZ PÉREZ
}

El propósito de este artículo es entender de manera integral el papel que tienen los palos del telar de cintura, en específico el instrumento conocido como machete o tzotzopaztli, en una serie de relatos de comunidades zapotecas del sur de Oaxaca, en los que personajes como naguales y vírgenes tutelares utilizan estos palos como armas para pelear y defender a los pueblos. En nuestro análisis, revisamos imágenes de códices mexicas en los que aparecen diosas asociadas con el tejido y la guerra. Otras fuentes importantes para nuestro análisis son escenas de códices mixtecos, así como objetos arqueológicos de los valles centrales de Oaxaca. El objetivo es aportar elementos que enriquezcan el planteamiento de la relación simbólica entre el tejido y la guerra en Mesoamérica.

PALABRAS ClaVE: tradición textil, diosas del tejido, guerra y tejido, zapotecos del sur, cosmovisión mesoamericana

Women Weavers, Warrior Goddesses: Textile Tradition in the Zapotec Region of Southern Oaxaca

The purpose of this article is to understand in an integral way the role of the waist stick looms in stories from Zapotec communities in the south of Oaxaca, where characters like virgins and naguales use these sticks as weapons to fight and defend the people. We reviewed images from Aztec codices where goddesses appear and they are associated with fabric and war. Other important sources for our analysis are scenes of Mixtec codices, as well as archeological objects from the central valleys of Oaxaca. The main goal is to provide elements that support the approach of the symbolic relationship between the tissue and the war in Mesoamerica.

DAMIÁN GONZÁlez PÉREZ

Instituto de Investigaciones Estéticas, Universidad Nacional Autónoma de México, KEYWORDs: textile tradition, weaver goddesses, weaving and war, Zapotecs of the south, mesoamerican worldview

Ciudad de México, México damiangp313@hotmail.com 


\section{Presentación'}

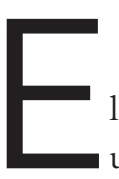

1 tema de la tradición textil en varias regiones de Mesoamérica ha recibido

un interés notable en años recientes. Con frecuencia, estos estudios recurren a la tradición oral vigente entre las comunidades tejedoras para contextualizar el problema de estudio. En nuestro caso, nos interesa entender el sentido simbólico que tienen o tuvieron hasta hace algunos años los utensilios asociados con el tejido en telar de cintura, en particular el palo conocido como machete o espada, denominado dzib en las variantes de Santa Catarina Quioquitani y San Pedro Mixtepec, ${ }^{2}$ cuyo término es una derivación del nombre asignado a objetos de metal o fierro, entre ellos el machete, el hacha, la plancha de carbón y el cardador, entre otros. En ambas comunidades se emplean también los términos chochopastle o chuchupastle, cuyas voces son asumidas por los zapotecos de la región como términos en español. En realidad, son deformaciones de la voz nahua tzotzopaztli. Este instrumento se menciona en una serie de relatos de comunidades zapotecas del sur de Oaxaca, en específico de los distritos de Miahuatlán y Yautepec, en la región de la Sierra Sur.

Entre las características del telar de cintura, debe destacarse su practicidad. Su mecanismo permite montar el telar en casi cualquier lugar, sólo basta un objeto que sirva como poste, para que la tejedora despliegue los hilos de la urdimbre, apoyada en una serie de palos que miden entre 60 y 70 centímetros de largo, los cuales

$1 \quad$ Agradezco a los arqueólogos Robert Markens, Marcus Winter y Raúl Matadamas por compartir información sobre algunos contextos arqueológicos en los que se han encontrado objetos asociados con el tejido. A ellos y a Alejandro de Ávila agradezco también algunas sugerencias bibliográficas.

2 En la región de la Costa, distrito de Juquila, hay una comunidad que se llama también San Pedro Mixtepec. En este trabajo, nos referimos a la comunidad zapoteca de San Pedro Mixtepec, perteneciente al distrito de Miahuatlán. 
definen la dimensión horizontal del telar. Es decir, el telar puede tener entre 60 y 70 centímetros de ancho. Su longitud depende del tipo de tejido que se elabore. El machete suele tener una mayor extensión, pues la tejedora lo toma por los extremos y lo jala hacia ella para apretar los hilos horizontales de la trama que va intercalando entre la urdimbre, es decir, los hilos verticales del tejido (véase la figura 1).

En ocasiones, el machete se relaciona con el acto de propiciar la lluvia. En las regiones nahuas de Chicontepec, Veracruz, y en la Sierra Norte de Puebla, así como entre los popolocas de San Pedro Soteapan, Veracruz, este instrumento se concibe como un cetro que utilizan las entidades regentes de la lluvia para provocar rayos, y en sentido opuesto, para partir las nubes y evitar las tormentas. Bernardino de Sahagún proporciona un referente significativo cuando menciona que en la fiesta mexica de Atemiztli, dedicada a las deidades de la lluvia, el tzotzopaztli era utilizado para sacrificar de manera ritual representaciones de cerros hechas de masa: “metíanselo por los pechos a las imágenes de los montes, como matándolas, y cortábanles el cuello y sacábanles el corazón” (Sahagún, 2006: 16).

Como parte del complejo ritual asociado con el nacimiento de niñas, era costumbre amarrar a la

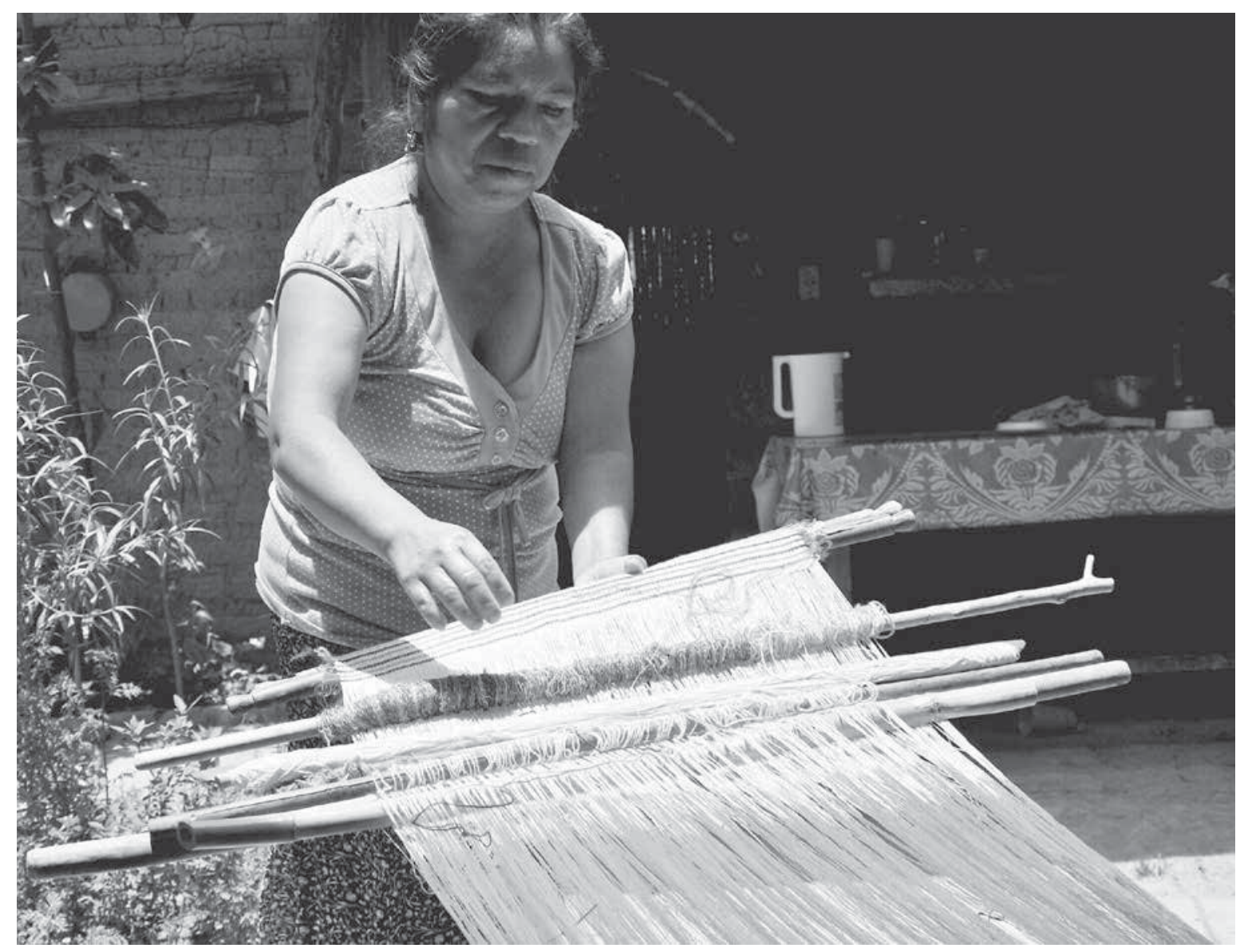

Figura 1. Señora Lucía, tejedora de Quioquitani, mostrando su telar de cintura, agosto de 2015 (foto: Damián González Pérez). 
cuna de las recién nacidas telares en miniatura para que fueran buenas tejedoras. Esto ocurría entre los nahuas de Santa Ana Tzacuala, Hidalgo, y los nahuas de Cuetzalan, Puebla (Stresser-Péan, 2003: 428). Motolinía da testimonio de la misma tradición entre los nahuas del altiplano, cuando señala que a los cuatro días del nacimiento de una niña, la partera o tícitl colocaba entre sus manos una escoba, un malacate para hilar, un tzotzopaztli para tejer y un petate. En cambio, si era niño, le entregaba un arco, cuatro flechas y reproducciones en pequeño de los instrumentos utilizados por su padre en el trabajo (citado en Mompradé y Gutiérrez, 1981: 18).

El tejido ha acompañado a las mujeres a lo largo de su vida en varias regiones. En comunidades zapotecas del sur, hasta hace pocos años las madres tejedoras o los padres de las niñas acostumbraban confeccionar palos para tejer en tamaño reducido, con los cuales las niñas jugaban cuando acompañaban a los adultos al campo. Estos juegos se completaban con el uso de hilos burdos. Luego de una vida dedicada en su mayor parte a tejer, cuando fallecían, las tejedoras eran enterradas con los palos que habían usado, su huipil, su torsal o tlacoyal, su enredo o manta xona, y su ceñidor o sollate. Esto sucedía en comunidades zapotecas del sur, como San Bartolo Yautepec, San Agustín Loxicha, Santo Tomás Quierí, San Juan y San Pedro Mixtepec, entre otros (véanse las figuras $2 \mathrm{a}$ y 2 ).

Como se señaló, nos interesa entender el papel del machete en la tradición oral de comunidades zapotecas del sur de Oaxaca. Los relatos que presentaremos aluden a conflictos entre comunidades, en los que mujeres nagualas y santas patronas pelean y usan este instrumento como arma. En el análisis recurrimos, inicialmente, a escenas de códices mexicas en los que aparecen diosas relacionadas con el tejido, quienes portan un machete y otros implementos del tejido, así como armas de guerra. El análisis continúa con la consideración de imágenes de códices y material arqueológico de la tradición mixteca, cuyo simbolismo muestra el sentido ritual que pudo tener el machete o tzotzopaztli en ciertos contextos ceremoniales. Por último, consideramos

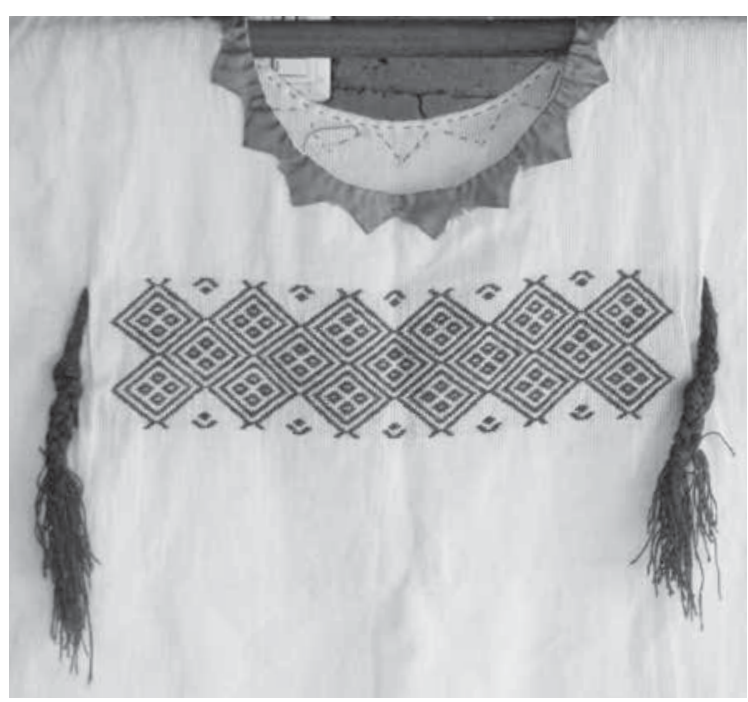

Figura 2a. Detalles del cuello y el pecho en el huipil de Santo Tomás Quierí, octubre de 2015 (foto: Damián González Pérez).

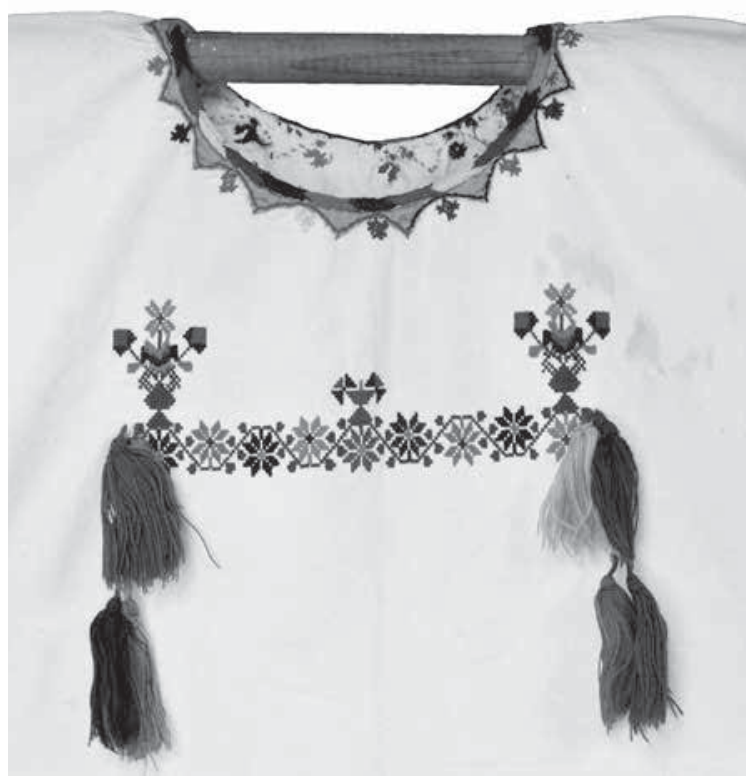

Figura 2b. Detalle del cuello del huipil de Santa Catarina Quioquitani, agosto de 2015 (foto: Damián González Pérez). 
referentes tanto iconográficos como etnohistóricos provenientes de regiones zapotecas para contextualizar de manera más general la importancia del tejido en la tradición cultural zapoteca.

\section{Mitos y tejidos de los zapotecos del sur}

El primer relato que presentaremos es de San Pedro Mixtepec, pueblo zapoteco ubicado en la región de la Sierra Sur de Oaxaca, en el distrito de Miahuatlán, donde se conserva una historia que refleja parte del simbolismo que tuvo en su momento el tejido en telar de cintura. Se cuenta que algunas personas de un pueblo vecino llamado San Pedro Leapi fueron a ver a un platero para encargarle un candelabro, que sería un regalo para su santo patrón, pues se aproximaba su fiesta. Justo cuando el platero terminó el trabajo, llegaron personas de San Pedro Mixtepec. El platero preguntó: “¿de dónde vienen?”. Las personas respondieron de inmediato, sin conocer la historia del candelabro: "somos de San Pedro". El platero, convencido, entregó el candelabro a los de San Pedro Mixtepec, quienes regresaron a su pueblo satisfechos con su compra.

Al enterarse de lo ocurrido, la gente de San Pedro Leapi se molestó y en venganza envió un nagual de culebra para acabar con el otro San Pedro. La culebra fue al río que atraviesa el pueblo de Mixtepec y se colocó en la parte baja, formando una hondura. El nivel del agua comenzó a crecer hasta que el río estuvo a punto de desbordarse e inundar el pueblo.

Para evitar una catástrofe, las personas de San Pedro Mixtepec fueron al pueblo huave de San Mateo del Mar, en la región del Istmo de Tehuantepec, considerado desde hace mucho tiempo en distintas regiones de Oaxaca como un sitio de donde proceden naguales. Allá preguntaron a los ancianos, personas sabias, cómo hacer para pelear contra el nagual enemigo y salvar a su pueblo. Algunas versiones relatan que los abuelos de San Mateo del Mar les dijeron que regresaran a la sierra, al pueblo de Santo Tomás Quierí, a pedir ayuda. En otras versiones, los abuelos no recuerdan a qué pueblo los mandaron los mareños. ${ }^{3}$ Invariablemente, en el pueblo referido, los de Mixtepec encontraron a una mujer $m d z i t$, es decir, nagual de cometa.

Luego de platicar un rato, ella aceptó ayudarlos. Les dijo que regresaran a su pueblo y esperaran unos días, porque acababa de dar a luz. Ya recuperada, la mujer llegó a San Pedro y explicó a las personas que pelearía con el nagual de culebra enviado por los de San Pedro Leapi. Para ello, se metería en un cerrito que queda justo frente a Mixtepec, de ahí aparecería en la hondura donde estaba la culebra. Les advirtió que si durante la pelea veían espuma blanca sobre el agua, ella habría ganado; pero si salía espuma roja, el nagual culebra destruiría a San Pedro Mixtepec.

Antes de entrar, la mujer nagual de cometa pidió a las mujeres sanpedreras que al comenzar la pelea lanzaran sus palos del telar de cintura y los lienzos tejidos en el telar hacia el agua, para que ella los usara como armas en la contienda. Entonces la mujer nagual fue hacia el cerrito y se metió en una piedra. De repente, se escuchó un tronido muy fuerte, como de un rayo, y la mujer apareció en la hondura y comenzó la pelea. Al final, el nagual de cometa ganó, cortó a la culebra con un palo de machete y la piedra en la que se metió para pelear contra la culebra enemiga lleva ahora ese nombre: $K i$ Mdzit, Piedra de Cometa.

Muy cerca de ahí, en la comunidad de Santo Tomás Quierí, de donde provenía la mujer nagual de cometa, existe un relato que puede considerarse complemento del anterior. Se cuenta que en cierta

3

El término "mareño" es empleado en diversas regiones de Oaxaca por comunidades que hablan otras lenguas para designar a los habitantes de los pueblos de la región huave, pues los nombres de esas localidades hacen referencia al mar: San Mateo del Mar, San Francisco del Mar, San Dionisio del Mar, etcétera. 
ocasión el pueblo vecino de Santo Domingo Lachivitó tuvo un enfrentamiento con el pueblo de San Mateo del Mar. Las personas de San Mateo enviaron un nagual de culebra como venganza, quien llevó consigo una lluvia muy fuerte, además de viento y derrumbes. Varias casas y milpas fueron destruidas, incluso la iglesia del pueblo. Cuando los de Santo Domingo supieron que la gente de San Pedro Mixtepec había acudido a Santo Tomás Quierí para buscar ayuda contra el nagual enviado por San Pedro Leapi, hicieron lo mismo.

En Quierí, los de Santo Domingo conocieron a la familia de la mujer nagual de cometa y a sus hijos gemelos, una niña y un niño, a quienes pidieron que pelearan contra la culebra de San Mateo del Mar. Ellos aceptaron, con la condición de que durante la pelea nadie los despertara, pues se llevaría a cabo mientras ellos dormían. La madre de los gemelos advirtió que habría una tormenta muy fuerte, acompañada de viento y lluvia, como consecuencia de la pelea, y que en ese momento las mujeres debían lanzar sus palos del telar de cintura, en especial sus machetes, pues los niños cometa los usarían como espadas contra la culebra huave. La madre cometa también dijo que si salía espuma blanca en el lugar donde estaba la culebra, sería señal de la victoria de los gemelos; pero si la espuma era roja, la culebra los habría derrotado.

Casi al final de la pelea alguien despertó al niño cometa. A pesar de que apareció espuma blanca sobre el agua, el niño murió junto con la culebra huave. Luego de esto, Santo Domingo tuvo que dar como pago a Santo Tomás Quierí un terreno de casi 100 hectáreas, que desde entonces pertenece al segundo pueblo.

Un tercer relato que puede considerarse parte de este corpus pertenece a la tradición oral de Santa Catarina Quioquitani, colindante con San Pedro Mixtepec. Se dice que entre ambos pueblos hubo un conflicto territorial. San Pedro intentó atacar a Quioquitani desde la parte alta del cerro donde se ubica. Una vez en la cima, alguien de Mixtepec miró con un catalejo hacia Quiouitani y vio que las mujeres del pueblo estaban formadas, listas para la pelea, armadas con una espada, en la misma postura que la imagen de la santa patrona dentro de la iglesia. De hecho, quien encabezaba el grupo era precisamente ella, Santa Catalina de Alejandría, portando su espada. Detrás de ellas estaban los hombres, todos con escopetas. Al ver esto, las personas de Mixtepec decidieron retirarse y claudicar.

Sin embargo, en Santa Catarina Quioquitani se tiene la certeza de que esto no sucedió. Al contrario, se dice que la gente del pueblo dio por sentado que los de San Pedro ganarían, pues iban acompañados de personas de otras comunidades, quienes también querían atacar Quioquitani y quedarse con parte de su terreno. En algunas versiones, sobre todo de mujeres mayores, se narra que los de Mixtepec vieron en realidad "una ilusión", en la que aparecían las mujeres de Quioquitani sujetando su machete del telar o tzotzopaztli, y las de Santa Catalina de Alejandría, listas para pelear.

\section{Diosas del tejido y de la guerra en códices mexicas}

Para entender desde una perspectiva más general el sentido del machete o $d z i b$ en estos tres relatos, recurriré a la revisión de contextos en los que los componentes del telar de cintura pudieron estar asociados a armas empleadas en una batalla. En nuestro análisis consideramos un corpus de diosas mexicas, reconocidas por Báez-Jorge como diosas de la fertilidad, la agricultura y la tierra, todas vinculadas con Tlazolteotl (1988: 123-124). Entre estas diosas se encuentran Cihuacoatl, Xochiquetzal, Chalchiuhtlicue, Coatlicue, Ilamatecuhtli, Itzpapalotl e Ixcuina. En ellas se conjuga la vida con la muerte, tal vez el sacrificio es el acto que enlaza dichos ámbitos. Soustelle (2003: 109-110) destaca la atribución de la 
maternidad de algunas de ellas, grandes madres de las que nacieron a su vez otros dioses relacionados con las artes, las flores y el maíz.

El carácter de Tlazolteotl y de otras deidades como diosas patronas del hilado y el tejido es claro por sus distintivos, que corresponden, precisamente, a los utensilios empleados en esas actividades. Uno de ellos es su tocado, en el que aparecen con frecuencia dos husos con malacate e hilo de algodón hilado o sin hilar y con copos de algodón colgando de ellos. El tocado y las cintas de sus aretes están formados también por una banda de algodón sin hilar.

Uno de los nombres de Tlazolteotl era Ixcuina, cuya etimología deriva posiblemente de los vocablos teenek, ix, "mujer", y cuinin, "algodón", es decir, "señora o diosa del algodón" (Sullivan, 1982: 12). Para Thelma Sullivan, los elementos de algodón propios del atavío de la diosa, como las orejeras, la diadema y el tocado en general, tienen un carácter gráfico, pues denotan explícitamente su nombre (1982: 12-13). ${ }^{4}$

Además de ser una deidad del tejido, Tlazolteotl tenía también una connotación bélica, referida por Diego Durán en la descripción de la fiesta mexica de Ochpaniztli, que se hacía en su honor (1995: 148-154, 254-256). Un lugar significativo durante la fiesta era un templo ubicado en la entrada de la ciudad de Tenochtitlan, cuyo nombre era Cihuateocalli, "iglesia u oratorio de mujeres" (1995: 148). Ahí había una estatua de madera de la diosa anciana Toci-Tlazolteotl, madre de los dioses, con el rostro aderezado de color blanco de la nariz hacia arriba y de negro la parte de la boca, con pintura de hule. En la cabeza tenía una banda o diadema de algodón, la cual sujetaba dos husos con hilo de algodón, de los que colgaban a su vez copos de algodón ya cardado. Además, la escultura porta en una mano una rodela y en la otra una escoba (1995: 149).

Para la realización de Ochpaniztli, elegían 40 días antes a una mujer de entre 40 y 45 años de edad, quien representaría a la diosa y luego sería sacrificada. La mujer permanecía encerrada hasta siete días antes de la celebración, cuando era entregada a siete mujeres de edad mayor, médicas y parteras. El primero de esos siete días, las ancianas entregaban a la mujer una carga de henequén para que lo limpiara, lavara e hilara y con él tejiera su propio huipil y enagua. La víspera de la fiesta, la mujer era llevada al tianguis, donde fingía vender las prendas que había tejido. Con ello, se recreaba de manera ritual el momento primordial en el que la diosa dedicaba su tiempo a hilar y tejer para ganar dinero y mantener a su prole divina.

Luego del sacrificio, el cuerpo de la mujer era desollado y la piel colocada en un hombre vivo, quien representaba ahora a la diosa, vistiendo el mismo huipil y enagua, así como la corona de algodón y los husos con hilo. Ya ataviado, lo sacaban en público, acompañado de servidores equipados como si fueran a la guerra. Al mismo tiempo, los nobles y caballeros más importantes de la ciudad, armados con escudos y macanas, y protegidos con petos, fingían un combate. Más adelante se desataba, según Durán, "una grande y sangrienta contienda de palos y pedradas y era tanta la gente que acudía a la contienda y rebato que era cosa espantosa de ver" (Durán, 1995: 153; cf. Sahagún, 2006: libro 2, XI, 84; 2006: libro 1, VIII, 32).

Encontramos otra representación muy interesante de Tlazolteotl en la lámina 26 del Códice Cospi (1994), en la que la diosa porta en sus manos implementos de guerra, entre ellos un chimalli, un haz de flechas sin punta y un atlatl o lanzadardos. En la lámina 25 del mismo códice, hay una representación de la diosa Xochiquetzal con rasgos muy semejantes a los de la Tlazolteotl de la lámina anterior, pero en este caso el personaje respectivo porta en una mano

$4 \quad$ En Rincón (1997: 22-25), encontramos un análisis sobre la etimología de la palabra ixcuina, en el que se consideran distintas fuentes. 


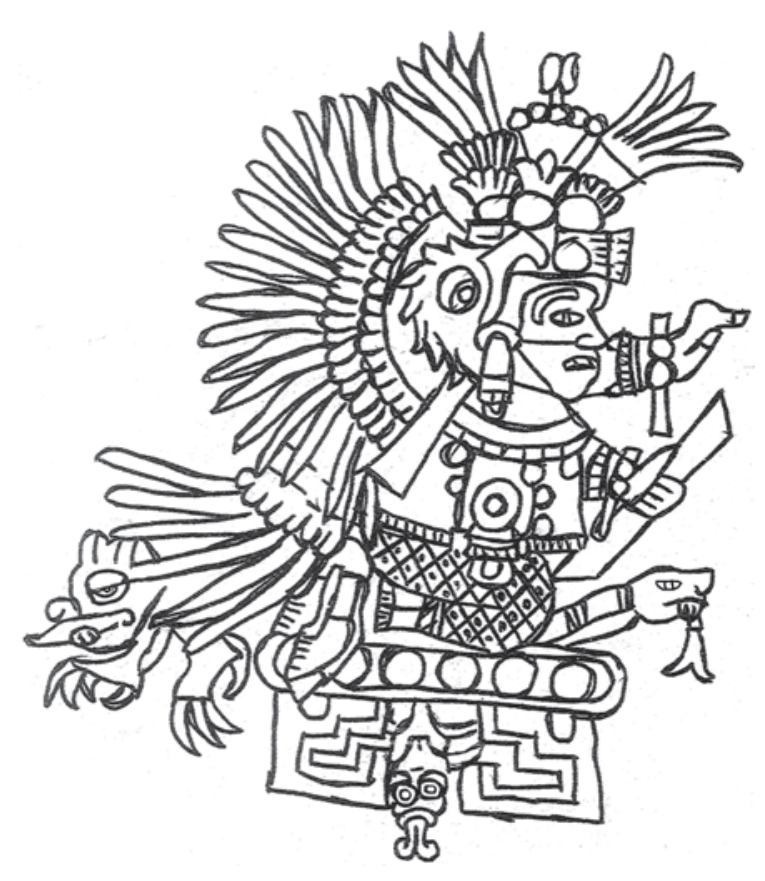

Figura 3. Xochiquetzal porta un tzotzopaztli (Códice Telleriano-Remensis, 1998: lám. 22v).

el escudo y las flechas sin punta, y en la otra dos husos, uno con hilo de algodón y el otro con algodón sin hilar. Ambos personajes están sentados sobre fauces de lagarto.

Anders, Jansen y Van der Loo (en Códice Cospi, 1994: 313-318) consideran que ambas láminas están relacionadas con ofrendas asociadas a la actividad de tinción, debido a los animales que aparecen en la parte de arriba de las láminas. Uno de ellos podría ser un caracol púrpura y el otro un gusano de nopal, lo que implicaría que los rituales representados estarían asociados a la extracción de dos de los principales pigmentos para el tejido en Mesoamérica: púrpura y rojo.

En el caso de Xochiquetzal, la encontramos en una situación semejante en el Códice TellerianoRemensis (1998). En la lámina 22v, Xochiquetzal sujeta con una mano un tzotzopaztli color turquesa, con un tocado con flor y un yelmo de quetzal. De su asiento asoman una serpiente y un felino, y de la parte de abajo un animal con lengua bífida, con el aspecto de un ciempiés. ${ }^{5}$ En la misma lámina se señala que Xochiquetzal fue la primera mujer que hiló y tejió, por ello las mujeres que se dedicaban a esta actividad le festejaban durante la fiesta de Tititl (véase la figura 3). En la lámina $\mathrm{V}$ del mismo códice, en la nota de la fiesta sobre Ochpaniztli, hay un detalle interesante. Se señala que Xochiquetzal era considerada la primera mujer que había pecado y que tenía otro nombre: Tlazolteotl. Sin embargo, el escribano lo tachó y anotó arriba Itzpapalotl, de quien se hablará posteriormente. ${ }^{6}$

En la fiesta de Pachtontli o Teotleco, según Diego Durán (1995: 151-158), se sacrificaba una mujer ataviada previamente como Xochiquetzal. Luego su cuerpo era desollado y puesto sobre un hombre, junto con el atuendo que había llevado la mujer. Así era sentado en las gradas del templo de Huitzilopochtli y le entregaban un telar de cintura para que se lo pusiera y fingiera que tejía. Este acto se hacía debido a la atribución de Xochiquetzal como patrona de las hilanderas y tejedoras, además de los pintores, plateros y demás personas que tenían por oficio algún arte similar. ${ }^{7}$

5 Los mismos elementos se observan en la lámina 17 del Códice borbónico (1991).

6 Según la información proporcionada por Durán (1995: 289290), en la fiesta de Tititl se rendía culto también al dios Camaxtli o Mixcoatl, dios chichimeca de la cacería y asociado también a la guerra. Se le consideraba el fundador de esta actividad, por ser el primer cazador y enseñar este arte a los hombres. Los sacrificios en su honor eran los de mayor número. Sin embargo, la mayoría de éstos no eran humanos, sino de animales del monte obtenidos mediante la cacería.

7 Otra fiesta en la que se rendía culto a Xochiquetzal era en la segunda fiesta movible, en la que las labranderas y tejedoras ofrendaban y sacrificaban en honor a la diosa (Sahagún, 2006: libro 2, XIX, 91). 


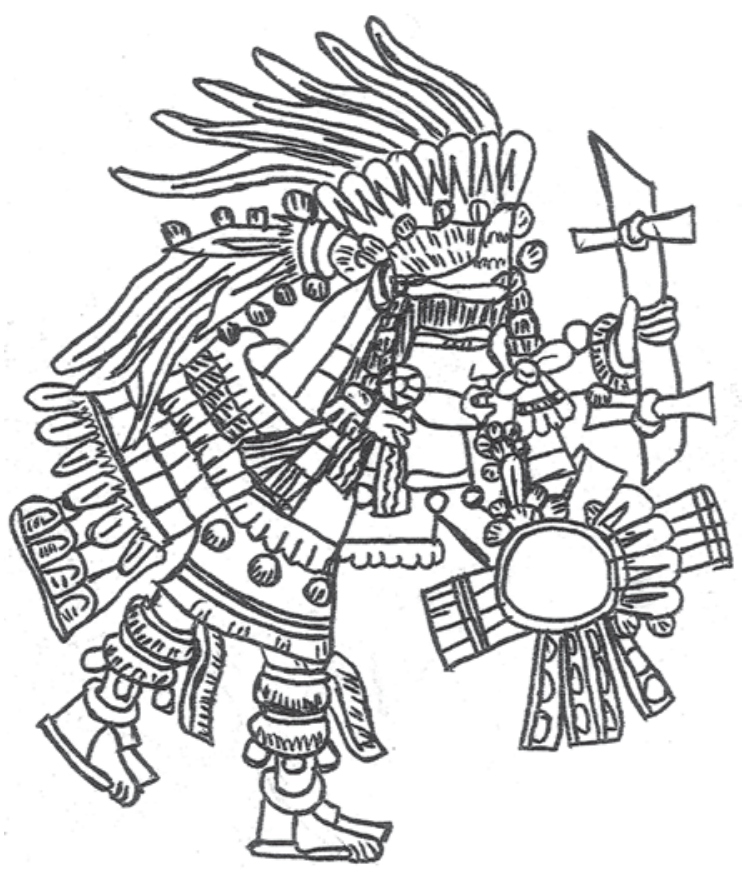

Figura 4. Mixcoatl porta escudo y tzotzopaztli (Códice Telleriano-Remensis, 1998: lám. 6).

En la fiesta de Quecholli, considerada "fiesta de la cacería", se realizaba precisamente una gran cacería colectiva en un cerro en el que se construía un adoratorio de nombre Mixcoatcocally, "lugar sagrado de Mixcoatl”. Luego de desplegar una emboscada a los animales, los participantes en la fiesta...

se venían a juntar a la coronilla del cerro donde la ermita estaba, trayendo por delante toda la caza y sabandijas del monte la cual viéndose cercada, pugnando por huir, ahí era el matar y flechar y tomar a mano venados, liebres, conejos, leones, gatos monteses y otras fieras ardillas, comadrejas, culebras (Sahagún, 2006: libro 2, XI, 84).

Los animales atrapados eran llevados ante la imagen de Mixcoatl y ahí eran sacrificados como si fueran cautivos de guerra. En otro momento, una esclava y un esclavo eran ataviados, ella como una diosa llamada Yoztlamiyahual y él como Mixcoatl. Su sacrificio denotaba los sentidos de la guerra, la cacería y la posesión de un nuevo territorio (2006: libro 2, XI, 85). Rituales sacrificiales como éste se realizaban también cuando un templo o edificio se consagraba, luego de su culminación o renovación (2006: libro 2, XI, 86).

Como muestra de la conexión entre la diosa Xochiquetzal, patrona de las hilanderas y las tejedoras, y Mixcoatl, Culebra de Nube, dios asociado con la guerra y la cacería, hay dos representaciones de este dios, una en la lámina XI del Códice Telleriano-Remensis (1998) y otra en la lámina 50v del Códice Vaticano A (1996: lám. 50v). En ambas, correspondientes a la fiesta de Tititl, Mixcoatl sujeta con una mano un tzotzopaztli adornado con dos cintas de papel, y con la otra un escudo con un haz de flechas sin punta, como sucede en algunas representaciones de las deidades femeninas referidas en este trabajo (véase la figura 4). En la fiesta, ambas deidades recibían culto: a Xochiquetzal la festejaban labranderas y tejedoras, y a Mixcoatl los cazadores.

Sahagún señala que esta misma fiesta estaba dedicada a Ilamatecuhtli (2006: libro 2, XXXVI, 144-146), cuyo segundo nombre era Tona o Tonantzin, Nuestra Madre, al igual que sucedía con Cihuacoatl. En una de las ceremonias de la fiesta, una mujer era sacrificada en honor a la diosa. Ambas compartían los mismos atavíos: un escudo y un tzotzopaztli. La cabellera de Ilamatecuhtli era la misma que tenía la diosa Toci-Tlazolteotl y le llamaban tzompilinalli (2006: Vocabulario, 929).

En relación con Mixcoatl, al revisar a Sahagún (2006: libro 2, XXXIII, 136-137), encontramos que en la fiesta de Quecholli, en la que se conmemoraba la guerra y la cacería, además de rendir culto a esta deidad, también se honraba a la diosa Coatlicue. Luego de la cacería colectiva en el cerro Zacatepetl, se hacían sacrificios en honor a ambos dioses. 
Los sacrificios tenían lugar a la medianoche del último día de la fiesta de Quecholli. Antes, los esclavos que morirían eran rapados de la coronilla. Las mujeres debían arrojar al fuego ciertos objetos emblemáticos: husos, arcilla con la que desmanchaban las telas, jícaras para hilar, estacas o palos para urdir el hilo, carrizos del telar, tzotzopaztli, lienzos, mecapales, cuerdas de ixtle para sujetar el telar y espinas o puntas de maguey usadas para apretar los hilos del tejido. Los hombres, por su parte, quemaban ropa, carrizos y vasos, entre otros objetos.

Otro personaje que tiene estrecha relación con Tlazolteotl es Chalchiuhtlicue, la de la Falda de Turquesa, diosa del agua de los ríos y las lagunas. En la primera lámina del Códice Fejérváry-Mayer (1994), en el rumbo del poniente del cosmograma, se encuentran ambas diosas flanqueando un huizache en cuya cima hay un colibrí. El Poniente era considerado el Cihuatlampa, "rumbo de las mujeres", al que llegaban las que morían en el parto y quienes adquirían un rango muy cercano a las deidades femeninas (Anders, Jansen y Pérez Jiménez, en Códice Fejérváry-Mayer, 1994: 168).

Hay una serie de escenas en otros códices que permiten entender la posible asociación entre ambas diosas. En las láminas VIII del Telleriano-Remensis (1998) y 17v del Vaticano A (1996), Chalchiuhtlicue está de pie y de ella emana un chorro de agua dentro del cual hay una mujer y un hombre. Éste porta un escudo y un haz de flechas. Delante de ellos va una caja de palma llena de frutos. El chorro de agua está rematado en sus bordes con caracoles y cuentas de piedras preciosas, lo que denota su calidad sagrada. La diosa tiene conchas de caracol en su tocado y falda, y en sus manos lleva un huso con hilo y copo de algodón, y un tzotzopaztli adornado con tiras de papel (véase la figura 5).

En la lámina 5 del Códice Aubin (Aguilera, 1981), Chalchiuhtlicue fue pintada, no con un huso y un tzotzopaztli, sino sujetando la cabeza de Tlazolteotl, tal vez como un acto ritual. Aquí la diosa está sobre un cetro y de él, al igual que las escenas del Telleriano-Remensis y Vaticano A, emana una corriente de agua con conchas y piedras preciosas. La corriente arrastra a una mujer y un hombre, quien tiene frente a sí una lanza. Este elemento, al igual que en los otros dos códices, connota la muerte de los guerreros caídos durante la batalla. Frente a Chalchiuhtlicue hay tres elementos asociados con ofrendas rituales: un brasero, un cofre tejido con cañas y una caja hecha con esteras (Aguilera, 1981: 8). ${ }^{8}$

Otra diosa importante en este complejo es Cihuacoatl, Mujer Serpiente, quien aparece en la lámina 10v del Códice florentino equipada con un tzotzopaztli y una rodela (Sahagún, 1979: 1, libro 1, lám. 10v). Cihuacoatl era llamada también

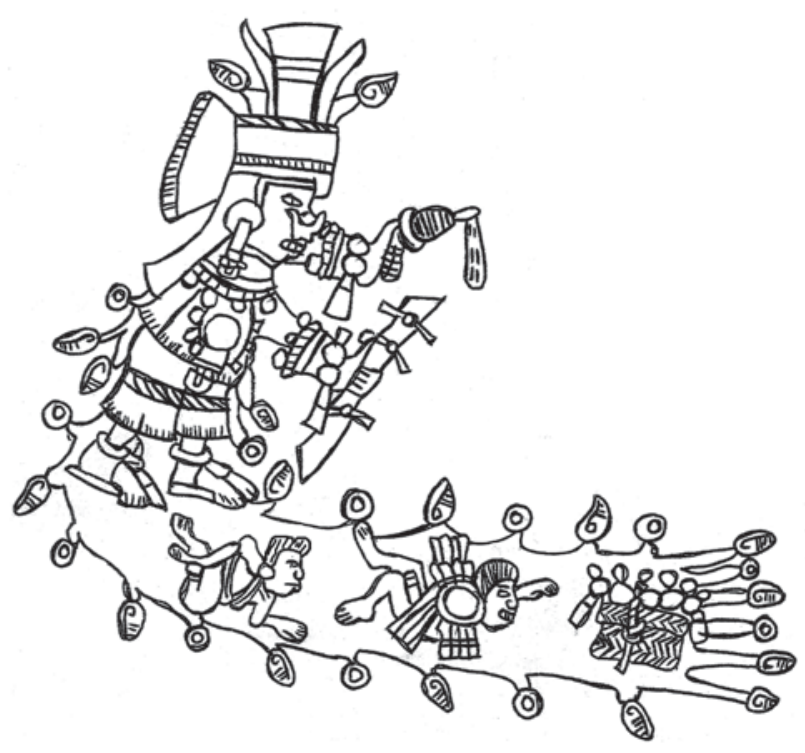

Figura 5. Chalchiuhtlicue sujeta con las manos un tzotzopaztli adornado con tiras de papel y un huso con hilo y copo de algodón (Códice Telleriano-Remensis, 1998: lám. VIII).

8 Dentro de esta serie debe considerarse también la lámina 54 del Códice Vaticano B (1992). 


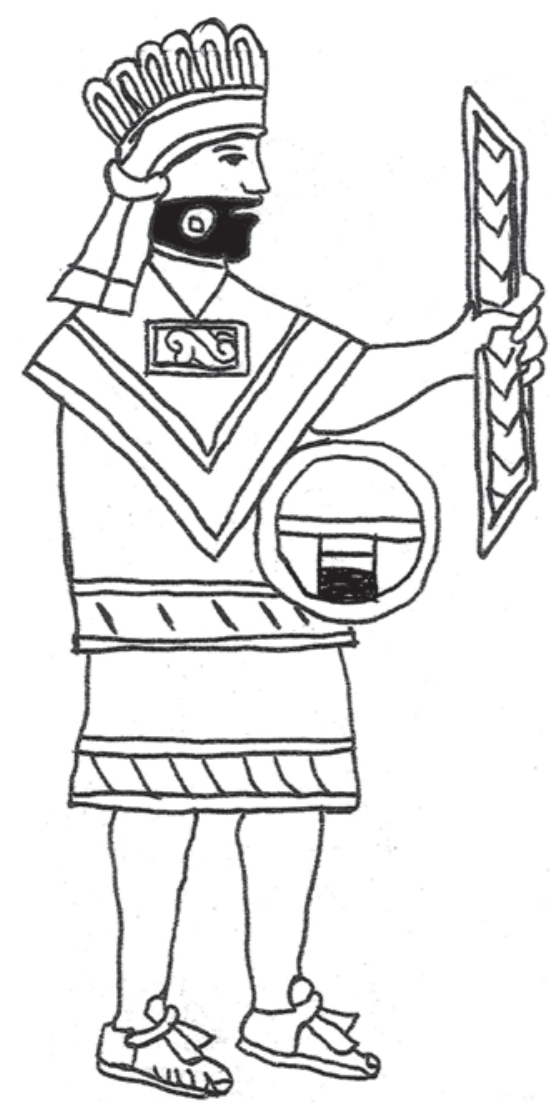

Figura 6. Personificación de Cihuacoatl con un tzotzopaztli y un chimalli (Sahagún, 2006: lám. 11a).

Tonantzin, Nuestra Madre, de quien se creía que "daba cosas adversas como pobreza, abatimiento, trabajos" (Sahagún, 2006: libro 1, VI, 31). Tenía como rasgos distintivos pintura facial roja en la parte superior de la cara y negra en la inferior; un tocado y escudo con plumas de águila y un tzotzopaztli (2006: Apéndices, 865). Además de su atavío, el canto que se le dedicaba connota su carácter de diosa guerrera, armada con su escudo y su palo para tejer: "Nuestra Madre, la Guerrera, Nuestra Madre, la Guerrera" (2006: Apéndices, 874). Según Irmgard Weitlaner Johnson, el tzotzopaztli de Cihuacoatl es de turquesa (1960: 81; cf. Sahagún, 1993: f. 253r; véase la figura 6).
En los códices Ixtlilxochitl (1996: lám. 102r) y Magliabechiano (1970) se representa de manera similar a Cihuacoatl, con lo que parece ser un tocado con algodón sin hilar y orejeras adornadas de la misma manera. En sus manos lleva también el tzotzopaztli y el escudo. En el mismo códice, la imagen de Cihuacoatl corresponde a la fiesta Tititl. En la lámina 44v del Codex Magliabechiano (1970), que corresponde también a la fiesta Tititl, Cihuacoatl aparece con los mismos rasgos que en el Ixtlilxochitl (véase la figura 7).

Al revisar las deidades de los códices que aparecen junto a elementos propios del tejido, encontramos también a Itzpapalotl, Mariposa de Obsidiana, asociada a la guerra. En el Códice Aubin (Aguilera, 1981: lám. 15), la diosa está sentada frente a un corazón, el cual, junto con el resto de la escena, connota sacrificio. Está posada en un cetro, debajo del cual hay una olla vertida de la que emana agua con cuentas de piedras preciosas y al lado un sahumerio con mango de serpiente.

En la parte central de la escena, está el árbol de Tamoanchan (Aguilera, 1981: 83), de cuyas ramas brotan flores y corazones. El árbol, que tiene su tronco torcido en espiral, está partido a la mitad y en los bordes del corte hay sangre. Sobre el árbol hay una codorniz sangrante también seccionada en dos partes. Del lado izquierdo del Tamoanchan hay una plataforma sobre la que se yergue el cuerpo de un hombre degollado, de cuya abertura salen dos cabezas de serpiente. ${ }^{9}$ Arriba del personaje degollado está la cabeza de un hombre con los ojos vendados.

9

Una de las interpretaciones que se ha hecho de esta plataforma indica que es una base de tzompantli, asimilada en distintos documentos pictográficos, en el periodo colonial, con la estructura en la que se ejecutaban la horca y la decapitación (Carreón, 2006: 5-52). 


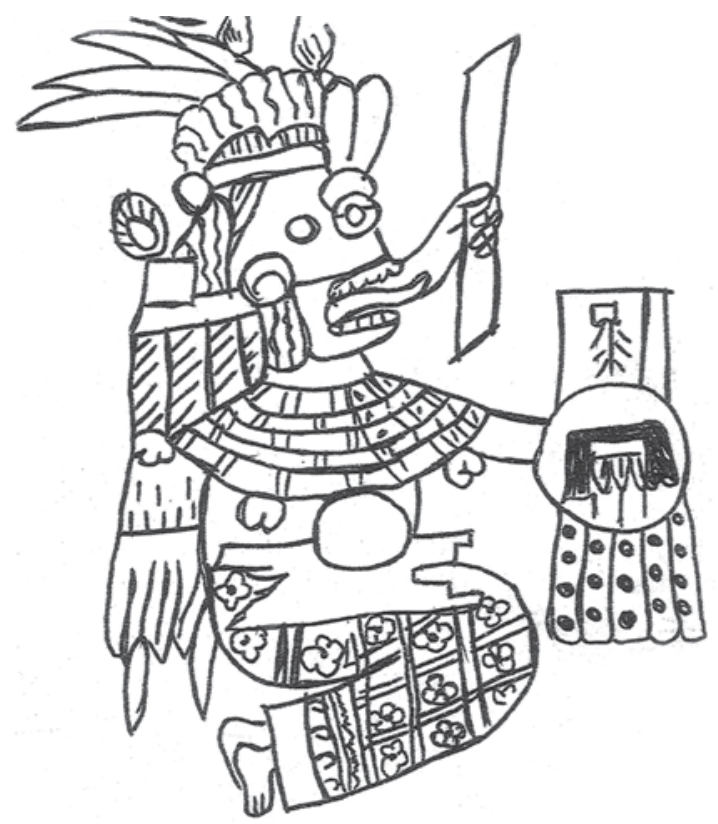

Figura 7. Cihuacoatl porta un tzotzopaztli y un chimalli (Códice Ixtlilxochit/,1996: lám 102r).

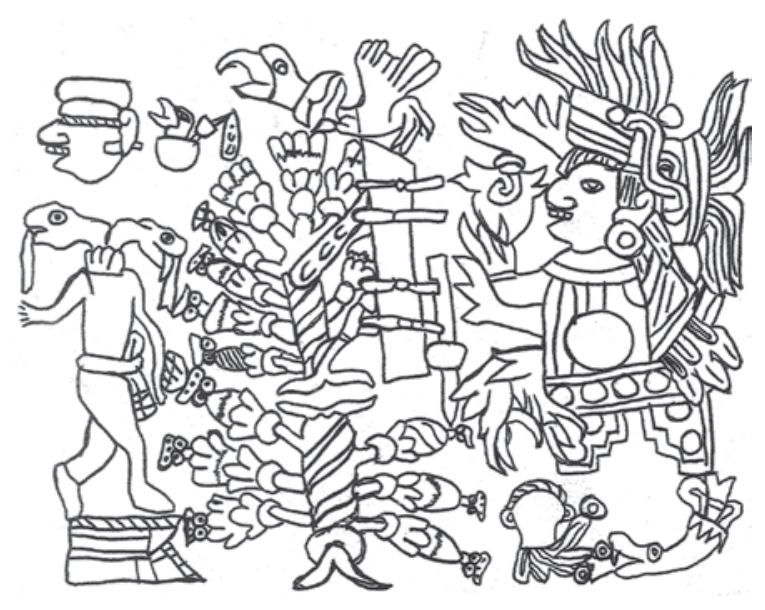

Figura 8. Itzpapalotl con elementos asociados al sacrificio y el tejido (Aguilera, 1981: lám. 15).

Además de estos elementos, en la lámina hay tres objetos importantes para nuestro análisis. Uno de ellos es una jícara que se encuentra en la parte superior izquierda, al lado del árbol de Tamoanchan. De la jícara asoma la cabeza de una codorniz y un huso con malacate del que cuelga un copo de algodón sin hilar. Los otros dos elementos son un tzotzopaztli de color azul, adornado con cuatro moños de papel blanco, del que se desprende, al parecer, una tira de algodón sin hilar. Junto a él hay otro huso con malacate, sin hilo ni algodón (véase la figura 8$).{ }^{10}$

\section{Implementos del tejido en contextos rituales de Oaxaca}

Además de los códices mexicas, existen otras fuentes en las que los utensilios para tejer parecen tener una connotación ritual. En este sentido, el estudio realizado por Weitlaner Johnson (1960) sobre un tzotzopaztli de madera hallado en una cueva cercana a Tehuacán, Puebla, en 1959, es un trabajo muy importante. El tzotzopaztli tiene una ranura a lo largo de la parte media de su cuerpo, dentro de la que se hallan siete semillas redondas, lisas y duras, de color café oscuro. Sobre lo que sería el lomo del machete, hay un grabado identificado por la autora como una posible variante del motivo iconográfico conocido como xicalcoliuhqui o greca escalonada (Weitlaner Johnson, 1960: 78; véase la figura 9).

El caso de este machete es extraño, debido en parte a sus dimensiones: $23 \mathrm{~cm}$ de largo, $2.25 \mathrm{~cm}$ de ancho y $1.1 \mathrm{~cm}$ de espesor. Además, el grabado y la ranura media con las semillas lo hacen muy peculiar. Weitlaner Johnson buscó en diversas fuentes pictográficas el significado de un tzotzopaztli

Weitlaner Johnson menciona que el tzotzopaztli cuelga del árbol de Tamoanchan. Sin embargo, esto no es claro en la escena, ya que del tzotzopaztli desciende una tira de algodón sin hilar hacia el árbol, pero la cinta no da vuelta sobre él, lo que implicaría más bien que el algodón sólo se desprende del machete (1960: 84). 


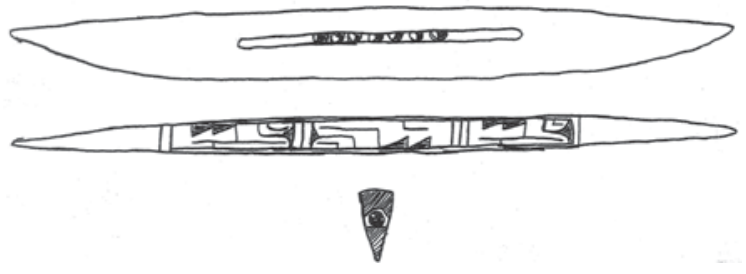

Figura 9. Dibujo del tzotzopaztli hallado en una cueva cercana a Tehuacán, Puebla (Johnson, 1960).

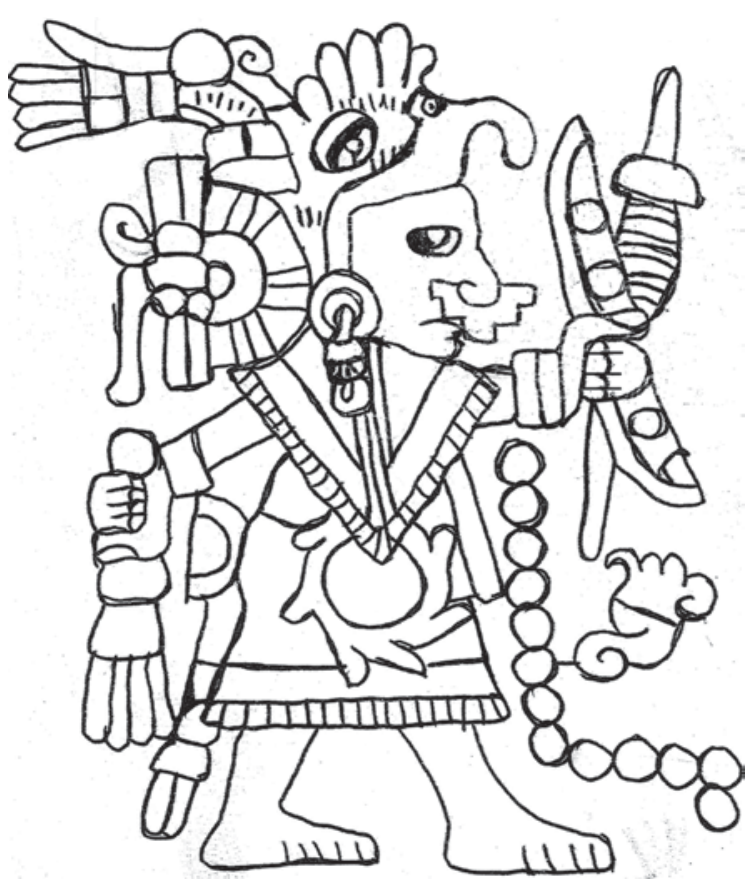

Figura 10. Señora 13 Flor, con atributos de Xochiquetzal, porta en una mano un huso con hilo y malacate, y un tzotzopaztli con cuatro o cinco círculos en el interior (Códice Nutall, 2007: lám. 19b).

como éste y concluyó que pudo haber tenido uso ceremonial. Un elemento que la lleva a esta conclusión es un dibujo de la lámina 19b del Códice Nutall (2007: 52), en el que aparece un personaje femenino con el nombre calendárico 13 Flor, quien ha sido identificado como una personificación mixteca de Xochiquetzal (McCafferty y McCafferty, 1994: 145-146). La Señora 13 Flor porta en una de sus manos un huso y un tzotzopaztli. Lo particular en el tzotzopaztli son los cuatro o cinco círculos pequeños en su interior, pintados de color amarillo. El resto es de color rojo. Una interpretación del objeto es que puede ser una sonaja. De cualquier manera, Weitlaner Johnson destaca su similitud con el tzotzopaztli hallado cerca de Tehuacán (véase la figura 10). ${ }^{11}$

Otro referente importante para entender el uso ceremonial de objetos como el tzotzopaztli es el corpus de huesos labrados encontrados en varios lugares de Oaxaca. Uno de los hallazgos más significativos fue el de la Tumba 7 de Monte Albán, con más de 40 huesos de águila y jaguar, entre los que pueden identificarse reproducciones de machetes para tejer o tzotzopaztli de tamaño reducido, agujas para separar o apretar los hilos del tejido y peines que se utilizaban con el mismo fin. Se encontraron también varios malacates, copas y cuencos para girar el huso con malacate e hilar. ${ }^{12}$

En un estudio relativamente reciente sobre el sentido y la composición de la famosa Tumba 7, McCafferty y McCafferty (1994) concluyeron que hay

Como parte su argumento, Weitlaner Johnson (1960) refiere algunas escenas de códices mexicas en las que aparecen deidades femeninas portando machetes del telar, algunas de las cuales forman parte de la revisión presentada en este trabajo. Sin embargo, no asocia de manera explícita las actividades del tejido a la guerra y la cacería.

12 En varios hallazgos arqueológicos de los valles centrales de los periodos Clásico y Posclásico, se distingue un patrón asociado a tumbas en las que fueron enterradas mujeres o personajes con atribuciones femeninas, que consiste precisamente en ejemplares de machetes para el tejido hechos con hueso, malacates, punzones de hueso, copas o cuencos para hilar y contenedores pequeños para guardar tintes e hilos (Robert Markens y Marcus Winter, comunicación personal, marzo de 2016). Sobre el posible sentido utilitario de algunas piezas de hueso, en correspondencia con Caso (1969), Jansen considera que la forma puntiaguda de algunas podría indicar su empleo como objetos para el autosacrificio (2012: 41). 
elementos suficientes para considerar el carácter femenino del personaje enterrado en la tumba en su última etapa de uso, es decir, durante el Posclásico. Esta postura contrasta con la de Alfonso Caso, quien no contempla la posibilidad de que el personaje principal de la tumba haya tenido atribuciones femeninas. En su obra clásica, El tesoro de Monte Albán, Caso (1969) describe con detalle los objetos hallados, entre los que destacan precisamente los tzotzopaztli, a los cuales llama "huesos labrados".

Es también importante señalar que, a pesar de que identifica en la iconografía de los "huesos tallados" personajes como la Señora 9 Caña, asociada por varios autores —entre ellos, el mismo Caso- a Tlazolteotl, esto no lo lleva a suponer una relación simbólica entre los objetos, el tejido y un posible personaje femenino. Al describir la escena del hueso catalogado con el número 203i, señala que la Señora 9 Caña o Tlazolteotl tiene, en una de sus manos, "lo que podría ser [...] el tzotzopaztli o palo para apretar el tejido al hilar, pues también se considera a la diosa (es decir, a Tlazolteotl), patrona de las hilanderas" (Caso, 1969; véanse las figuras 11a y 11b).

En otra escena, en el hueso 174a, la misma Señora 9 Caña sujeta con una mano una rodela, un haz de flechas y una bandera, y con la otra un mazo. $\mathrm{Su}$ tocado consiste en dos serpientes entrelazadas. Jansen, al comparar las escenas labradas de los huesos de la Tumba 7, en particular en éste, destaca la frecuencia con que la Señora 9 Caña fue representada en documentos pictográficos con un tocado de serpiente, como se observa en los códices Nutall y Vindobonensis (Jansen, 2012: 51; véanse las figuras 12a y 12b).

En oposición a la postura de Caso (1969), McCafferty y McCafferty consideran que objetos como los malacates y tzotzopaztli de la tumba son metáforas de las armas empleadas en la guerra, como macanas, flechas, lanzadardos y escudos (1994: 154). Argumentan la relación cíclica entre guerra-muerte-vida y el papel del poder femenino a

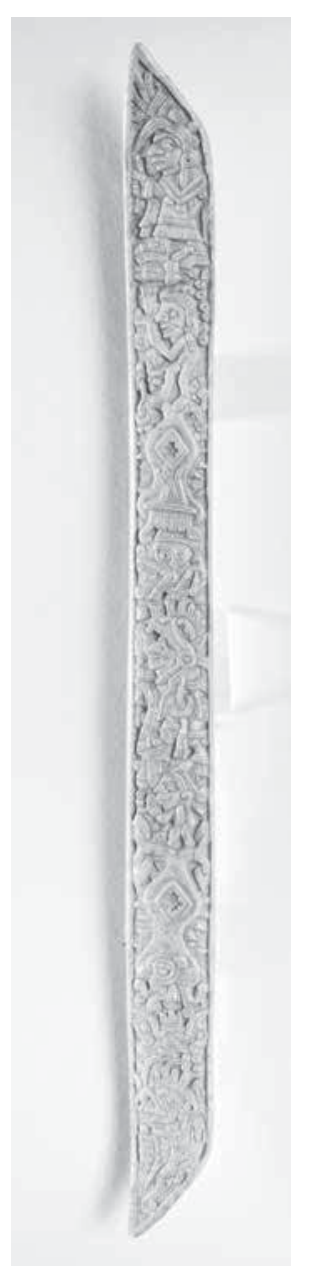

b

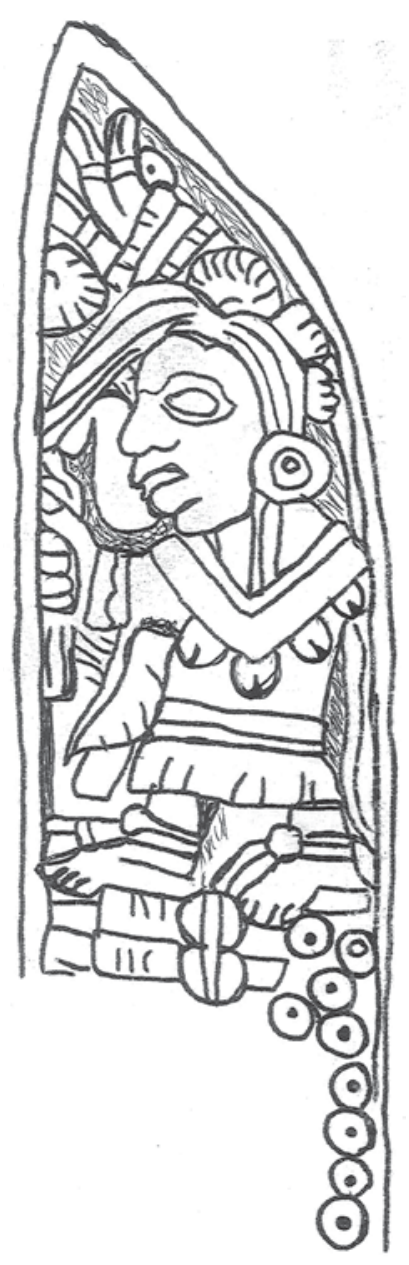

Figura 11a. Hueso labrado en forma de tzotzopaztli. Museo Regional de Oaxaca, cat. 203i. D. R. (c) Oliver Santana/Arqueología Mexicana 41/ Raices.

Figura 11b. Dibujo de un fragmento del hueso 203i. Se aprecia que la Señora 9 Caña porta un objeto identificado por Caso (1969) como un tzotzopaztli.

en la sociedad. Respecto de las diosas mexicas que aparecen en los códices y portan machetes, en particular Cihuacoatl, Ilamatecutli y Xochiquetzal, consideran una relación entre guerra y sacrificio, como paralelos de la muerte y la fertilidad (1994: 146). 

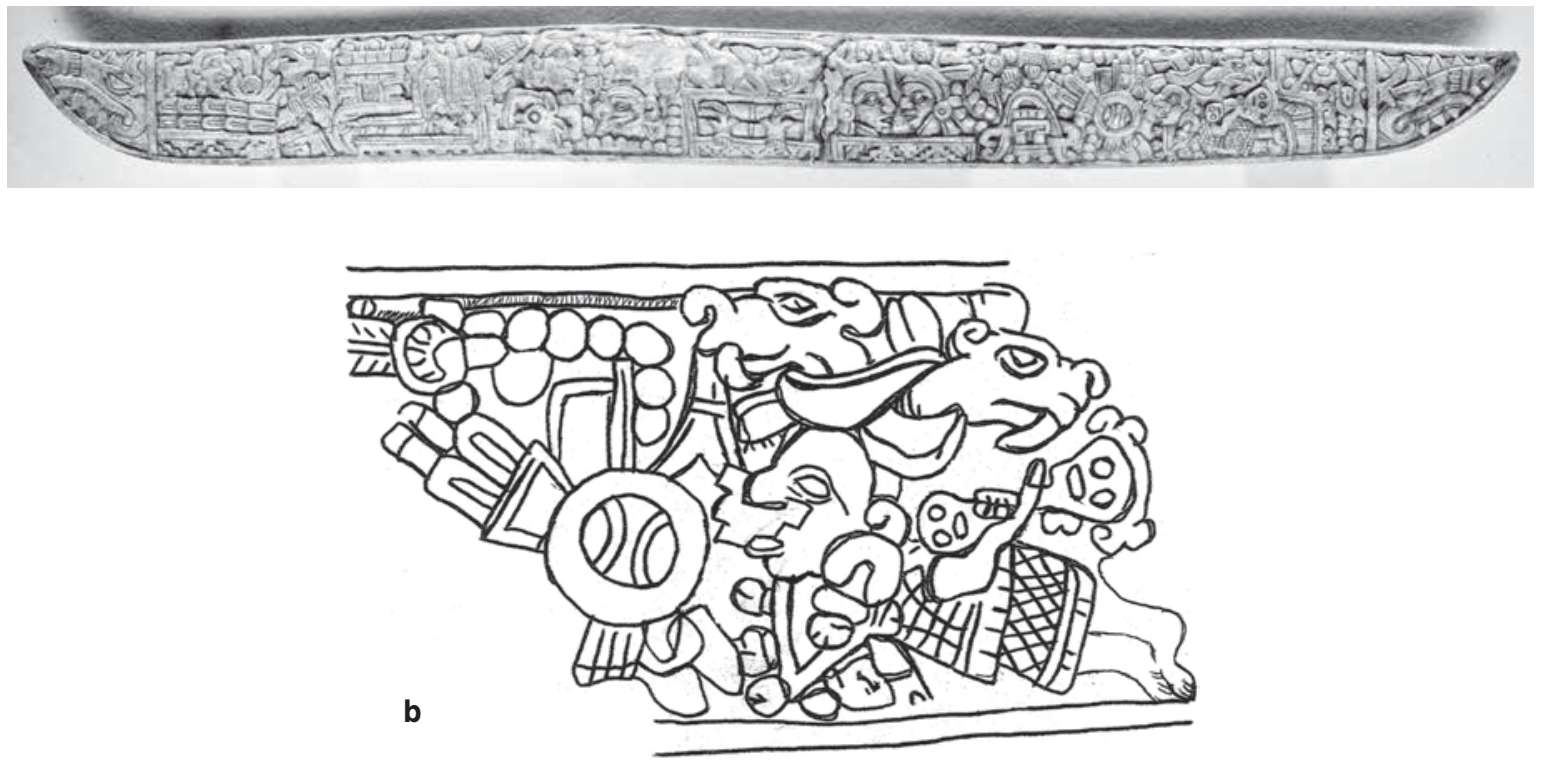

Figura 12a. Hueso labrado en forma de tzotzopaztli. Museo Regional de Oaxaca, cat. 174a. D. R. (c) Oliver Santana/Arqueología Mexicana 41/Raíces. Figura 12b. Dibujo de un fragmento del hueso 174a que muestra a la Señora 9 Caña con un escudo con flechas y una bandera en una mano, y en la otra, un mazo. En la cabeza lleva un tocado de serpientes entrelazadas (Caso, 1969).

Un elemento que permite a McCafferty y McCafferty reconocer como tzotzopaztli algunos de los huesos labrados, más allá de lo físico, es la mención de Bernardino de Sahagún sobre la manufactura de diversos tipos y tamaños de tzotzopaztli en la sociedad mexica. Algunos eran machetes pequeños y había otros que se hacían con hueso y se labraban (1994: 145).

\section{¿Hubo una diosa zapoteca vinculada al tejido?}

Desde cierta lógica, el análisis comparativo del simbolismo asociado a los implementos del tejido en telar de cintura - y de manera más general, del propio tejido- en Mesoamérica, como se ha desarrollado en este trabajo, implicaría el rastreo de las deidades femeninas zapotecas que formaron parte de este complejo. Sin embargo, la búsqueda es complicada debido a la falta de referentes en fuentes arqueológicas, históricas e incluso etnográficas. Un primer intento fue el de Laurette Sejourné, en su texto "Identificación de una diosa zapoteca", en el que llega "a la conclusión de que [el glifo J] se trata de una imagen compuesta de cápsulas de algodón abiertas" (1953: 112). Incluso, a partir de su interpretación iconográfica del glifo, se anima a "afirmar que la [Señora o Diosa] '2J' de las colecciones arqueológicas es la patrona del algodón" (1953: 113). Hace esta referencia a propósito de una serie de vasos y vasijas efigie zapotecos en los que aparecen personajes femeninos que llevan este glifo en el tocado, y en ocasiones, dos marcadores para el caso de las vasijas (véanse las figuras 13 y 14).

Uno de los argumentos generales que lleva a Sejourné a realizar esta búsqueda es la presencia e importancia de diosas del algodón y el tejido en diversos panteones mesoamericanos: 
Puesto que todos los sistemas religiosos de México han destinado un rango eminente a una divinidad relacionada con el tejido, sería poco verosímil que este mismo hecho no se hubiera producido en el seno de un pueblo que trabajó el algodón con más intensidad que ningún otro (1953: 113).

De la serie de registros disponibles sobre deidades zapotecas en diferentes contextos históricos y geográficos, Sejourné identifica a Nohuichana como equivalente de la Señora 2J, y por ende de Tlazolteotl, deidad vinculada a la fertilidad humana, los partos, el matrimonio, la vida y la pesca, que recibía culto en la región zapoteca de Sola de Vega a mediados del siglo XVII (Balsalobre, 1988; Berlin, 1988). Sejourné hace esta asociación aunque reconoce la ausencia del tejido en las atribuciones de Nohuichana y las demás deidades. Whitecotton (2004: 186) retoma directamente el planteamiento de Sejourné, pero no aporta mayores elementos cuando menciona que Nohuichana era diosa del algodón y el telar, así como de los partos, los niños y la creación.

Un primer elemento que impide considerar viable el planteamiento de Sejourné es la falta de correspondencia entre las nueve deidades identificadas en el panteón mexica y las listas de deidades zapotecas conocidas hasta ahora, las cuales derivan del Vocabulario en lengua zapoteca de Juan de Córdova (1987), del mismo proceso idolátrico de Sola de Vega (Balsalobre, 1988; Berlin, 1988), del manuscrito de San Antonio Huitepec (Van Meer, 2000) y de las deidades propias de la cuenta ritual de la región de Loxicha (Weitlaner y De Cicco, 1998). Dos autores realizan este ejercicio, Víctor de la Cruz (2007: 409-410) y Adam Sellen (2007), y correlacionan de manera distinta a varias de las deidades. Nohuichana es uno de los casos en que coinciden ambos, quienes la asocian a la Chalchiuhtlicue mexica, deidad del agua. En este complejo incluyen a Ndan, deidad primigenia, creadora de las demás deidades en el panteón de los zapotecos de la región de Loxicha.

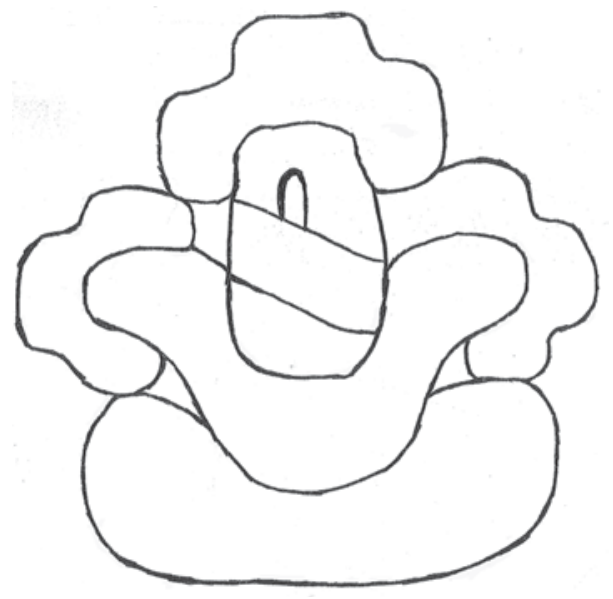

Figura 13. Representación del glifo J (Urcid, 2005).

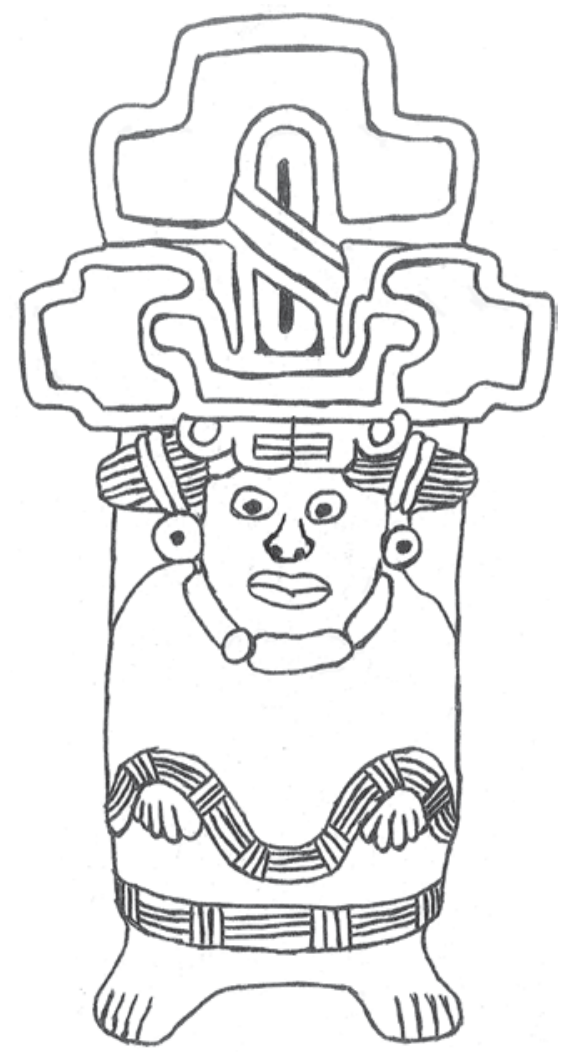

Figura 14. Vasija efigie de personaje femenino porta glifo J en el tocado y es posibles que un par de cuentas en los extremos inferiores del glifo. Museo Regional de Oaxaca. 
A las inconsistencias en las clasificaciones de De la Cruz y Sellen, se suma otro aspecto que debe considerarse en este tipo de equivalencias, y es que, en la información etnográfica recopilada por Roberto Weitlaner y Gabriel de Cicco en San Agustín, San Bartolomé, Santa Lucía y Magdalena, cuatro comunidades de la región zapoteca de Loxicha, existen diferencias significativas en las atribuciones, el género y el rango de las nueve deidades que rigen la cuenta ritual (Weitlaner y De Cicco, 1998; $c f$. González, 2014: 143-145, 208-213).

Además de Ndan, a quien De la Cruz (2007) y Sellen (2007) identifican como equivalente de Nohuichana y la Señora 2J, y Chalchiuhtlicue, cabe considerar el caso de Lexee, deidad de brujos y ladrones entre los zapotecos de Sola de Vega, causante de los sueños (Berlin, 1988: 22), a quien los autores equiparan con Tlazolteotl. Como parte de este complejo, De la Cruz y Sellen mencionan a Pitào Xicàla o Pixèe Pecàla, registrada por Juan de Córdova (1987) como deidad de los sueños y por Thomas Smith (2001: 127-129) como deidad del amor y la lujuria. De entre las nueve entidades del panteón de Loxicha, De la Cruz y Sellen la consideran equivalente a Mse, que en las cuatro comunidades visitadas por Weitlaner y De Cicco se describe como un "aire malo", equiparable con policías o topiles que ejecutan castigos dictados por las deidades, quienes solían tener a su servicio cierto número de Mse.

Además de la falta de elementos en fuentes lingüísticas, históricas y etnográficas que permitan validar la correspondencia de alguna deidad zapoteca con Tlazolteotl, otro punto crucial tiene que ver con el glifo J, identificado por Sejourné como una representación del algodón. Sellen (2007) y Javier Urcid (2005: figs. 1.20, 2.2) identifican explícitamente al glifo J como el glifo del maíz. ${ }^{13}$

A reserva de contar con un análisis más detallado sobre las referencias a diversas deidades en documentos alfabéticos, así como fuentes pictográficas correspondientes a localidades zapotecas, lo cual no es el propósito de este trabajo, consideramos que por el momento es difícil sustentar una equiparación entre los nombres de deidades zapotecas registrados en distintos lugares y periodos, así como sus atribuciones. Resulta poco viable también plantear que alguna deidad derivada de dichas fuentes sea patrona o creadora del tejido para los zapotecos. Sin duda, el trabajo etnográfico en varias regiones zapotecas de Oaxaca podría ser de ayuda para un análisis de este tipo.

\section{Consideraciones finales}

A lo largo de nuestro análisis, se han contrastado textos orales contemporáneos con imágenes iconográficas de huesos labrados del Posclásico, así como de códices prehispánicos y coloniales. Sin embargo, cabe preguntarse si el sentido de los primeros entre sus relatores y actores, que los tienen como parte de su tradición oral, se acerca a lo que en el pasado pudo ser un complejo cultural en el que el tejido y la guerra se entrelazaban. En ambos casos, hablamos de actos primigenios que fueron realizados por las deidades en el principio de los tiempos.

En el presente, la noción del tejido como acto primordial creado por diosas, que se observa con frecuencia en las crónicas coloniales, persiste en las comunidades de la región zapoteca del sur de Oaxaca. En San Juan Mixtepec, por ejemplo, hasta hace pocos años se creía que una virgen o diosa había inventado el tejido y ella misma había enseñado a tejer a las demás mujeres. Ella siempre estaba

13 El propio Sellen (2007) hace un análisis detallado de vasos y vasijas en los que aparece el glifo J o "maíz" e identifica diferencias en el número de marcadores que lo acompañan, cuando los hay. En ocasiones, corresponden a los nombres calendáricos de ancestros cercanos, frente a otros casos en los cuales los marcadores, por sus características, corresponderían más bien a personajes míticos. 
tejiendo, y como parte de la creencia, las personas mayores decían que si acaso terminaba de tejer su urdimbre, en ese mismo momento se acabaría el mundo. Por ello, todas las mujeres debían tejer para preservar esta tradición. El señor Hermilo Silva, originario de esta comunidad, recuerda que durante las tardes, cuando se sentaba a ver tejer a su abuelita, de repente giraba su mirada hacia el cielo, buscando el telar de aquella diosa, con la esperanza de que su tejido no estuviera a punto de terminarse (entrevista con Hermilo Silva, octubre de 2015). ${ }^{14}$

En los relatos que presentamos al principio, es explícito el sentido bélico de los implementos del telar. Cabe recordar lo señalado por McCafferty y McCafferty (2007) sobre la relación metafórica entre los palos para tejer y las armas, como se observa en varias escenas de códices mexicas, en las que las diosas portan objetos que aluden a dichos complejos, como hemos visto. Sin embargo, un análisis como éste debe considerar el papel de personajes históricos, los cuales tuvieron, al parecer, ambas atribuciones, como sucede con la Señora 9 Caña. Una revisión más detallada nos llevaría a identificar un corpus más amplio de este tipo de personajes, entre los que estaría, tal vez, la Señora 3 Pedernal. Recientemente, Cecilia Rossell y María de los Ángeles Ojeda (2003), en su libro Las mujeres y sus diosas en los códices prehispánicos de Oaxaca, subrayaron el papel de las mujeres nobles en contextos bélicos, a partir de escenas de códices mixtecos, aspecto que también es analizado y sustentado por McCafferty y McCafferty (2007).

Cabe reiterar la dificultad que existe hasta el momento para identificar posibles deidades zapotecas que pudieron asociarse específicamente al tejido. La información correspondiente a contextos zapotecos es aún escasa o ha sido poco estudiada. En este sentido, el trabajo comparativo es una vía para entender los contextos en los que la información actual es limitada, así como aquellos en los que la interpretación de las escenas correspondientes al pasado remoto no nos es del todo accesible. D

\footnotetext{
14 De manera similar, entre los huicholes y rarámuris fueron diosas quienes crearon el tejido y lo enseñaron a las mujeres (Aguilera Madrigal, 2011: 29, 40).
}

\section{Bibliografía}

\footnotetext{
Aguilera, Carmen, 1981, El tonalámatl de la colección de Aubin. Antiguo manuscrito mexicano en la Biblioteca Nacional de París (Manuscrit mexicains 18-19), Gobierno del Estado de Tlaxcala, Tlaxcala.

Aguilera Madrigal, Sabina, 2011, La faja ralámuli: un entramado cosmológico, Universidad Nacional Autónoma de México-Instituto de Investigaciones Estéticas/Instituto de Investigaciones Antropológicas, México.

Báez-Jorge, Félix, 1988, Los oficios de las diosas. Dialéctica de la religiosidad popular en los grupos indios de México, Universidad Veracruzana, Xalapa.

Balsalobre, Gonzalo de, 1988, "Relación auténtica de las idolatrías, supersticiones, vanas observaciones de los indios del Obispado de Oaxaca", en Idolatría y superstición entre los indios de Oaxaca, Toledo, México, pp. 91-135.

Berlin, Heinrich, 1988, Las antiguas creencias en San Miguel Sola, Oaxaca, México, en Idolatría y superstición entre los indios de Oaxaca, Toledo, México, pp. 7-89.

Carreón Blaine, Emilie, 2006, "Tzompantli, horca y picota. Sacrificio o pena capital”, en Anales del Instituto de Investigaciones Estéticas, vol. XXVIII, núm. 88, pp. 5-52.

Caso, Alfonso, 1969, El tesoro de Monte Albán, Instituto Nacional de Antropología e Historia, México.

Caso, Alfonso e Ignacio Bernal, 1952, Urnas de Oaxaca, Instituto Nacional de Antropología e Historia, México.

Codex Laud, 1966, introducción de Cottie Arthur Burland, Akademische Druck- und Verlagsanstalt, Graz.

Codex Magliabechiano, 1970, textos de Ferdinand Anders, Akademische Druck- und Verlagsanstalt, Graz.
} 
Códice borbónico. El libro del Ciuacóatl: Homenaje para el año del Fuego Nuevo, 1991, Akademische Druck- und Verlagsanstalt/Fondo de Cultura Económica/Sociedad Estatal Quinto Centenario, México y Viena.

Códice Cospi. Calendario de pronósticos y ofrendas, con textos de Ferdinand Anders, Maarten Jansen y Peter van der Loo, Akademische Druck- und Verlagsanstalt/Fondo de Cultura Económica, México.

Códice Fejérváry-Mayer. El libro de Tezcatlipoca, señor del tiempo, 1994, textos de Ferdinand Anders, Maarten Jansen y Gabina Pérez Jiménez, Akademische Druck- und Verlagsanstalt/Fondo de Cultura Económica, México.

Códice Ixtlilxochitl. Papeles y pinturas de un historiador, 1996, Akademische Druck- und Verlagsanstalt/Fondo de Cultura Económica, México.

Códice Nutall. Lado 2: La historia de Tilantongo y Teozacoalco, 2007, estudio e interpretación de Manuel Hermann Lejarazu, en Arqueología Mexicana, ed. especial 29.

Códice Telleriano-Remensis, 1998, en Antigüedades de México, v. I, Secretaría de Hacienda y Crédito Público, México.

Códice Vaticano A. Religión, costumbres e historia de los antiguos mexicanos, 1996, Akademische Druck- und Verlagsanstalt/Fondo de Cultura Económica, México.

Códice Vaticano B. Manual del adivino, 1992, Akademische Druck- und Verlagsanstalt/Fondo de Cultura Económica/Sociedad Estatal Quinto Centenario, México y Viena.

Córdova, Juan de, 1987, Vocabulario en lengua zapoteca, facs., Toledo, México.

Cruz, Víctor de la, 2007, El pensamiento de los binnigula’sa': cosmovisión, religión y calendario, con especial referencia a los binnizá, Instituto Nacional de Antropología e Historia/Centro de Investigaciones y Estudios Superiores en Antropología Social/Instituto Estatal de Educación Pública de Oaxaca/Casa Juan Pablos, México.

Diaz, Gisele y Alan Rodgers, 1993, The Codex Borgia: A Full-Color Restoration of the Ancient Mexican Manuscript, Dover, Nueva York.

Durán, Diego, 1995, Historia de las Indias de Nueva España e Islas de la Tierra Firme, t. I, Consejo Nacional para la Cultura y las Artes, México. González Pérez, Damián, 2014, Llover en la sierra. Ritualidad y cosmovisión en torno al Rayo y la lluvia entre los zapotecos del sur de Oaxaca, tesis de doctorado en antropología, Universidad Nacional Autónoma de México-Instituto de Investigaciones Antropológicas, México.

Jansen, Maarten, 2012, Monte Albán y la memoria mixteca: informe preliminar sobre investigaciones en proceso, Universidad de Leiden, Leiden.

McCafferty, Sharisse y Geoffrey McCafferty, 1994, “Engendering Tomb 7 at Monte Alban. Respinning an Old Yarn”, en Current Anthropology, vol. 35, núm. 2, pp. 143-166

—_, 2007, "Guerreras: el papel de las mujeres en la guerra prehispánica”, en Expresión Antropológica, núm. 29, pp. 32-39.

Meer, Ron van, 2000, "Análisis e interpretación de un libro calendárico zapoteco: el manuscrito de San Antonio Huitepec", en Cuadernos del Sur, año 6, núm. 15, pp. 37-74.

Mompradé, Electra L. y Tonatiúh Gutiérrez, 1981, Historia general del arte mexicano. Indumentaria tradicional indígena, t. 1, Hermes, México.

Rincón Huarota, Ricardo, 1997, Tlazolteotl Ixcuina. Un caso de sincretismo en la región mexica, tesis de licenciatura en arqueología, Escuela Nacional de Antropología e Historia, México.

Rossell, Cecilia y María de los Ángeles Ojeda, 2003, Las mujeres y sus diosas en los códices prehispánicos de Oaxaca, Centro de Investigaciones y Estudios Superiores en Antropología Social, México.

Sahagún, Bernardino de, 1979, Códice florentino, facs., Secretaría de Gobernación/Archivo General de la Nación, México.

__ 1993, Primeros memoriales, University of Oklahoma Press, Norman.

- 2006, Historia general de las cosas de la Nueva España, Porrúa, México.

Sejourné, Laurette, 1953, "Identificación de una diosa zapoteca”, en Anales del Instituto Nacional de Antropología e Historia, vol. 7, pp. 111-122.

Sellen, Adam T., 2007, El cielo compartido: deidades y ancestros en las vasijas efigie zapotecas, Universidad Nacional Autónoma de MéxicoCentro Peninsular en Humanidades y Ciencias Sociales, México.

Smith, Thomas, 2001, "Dioses, sacerdotes y sacrificio: una mirada a la religión zapoteca a través del Vocabvlario en lengva çapoteca (1578) de Juan de Córdova”, en Víctor de la Cruz y Marcus Winter (coords.), La religión de los binnigula’sa', Instituto Estatal de Educación Pública de Oaxaca, Oaxaca, pp. 91-195.

Soustelle, Jacques, 2003, La vida cotidiana de los aztecas en vísperas de la conquista, Fondo de Cultura Económica, México.

Stresser-Péan, Claude, 2003, “Un cuento y cuatro rezos de los nahuas de la región de Cuetzalan, Puebla”, en Estudios de Cultura Náhuatl, núm. 34, pp. 423-441. 
Sullivan, Thelma D., 1982, "TlazolteotI-Ixcuina: The Great Spinner and Weaver”, en Elizabeth Hill Boone (ed.), The Arts and Iconography of Late Post-Classic Central Mexico, Dumbarton Oaks, Trustees for Harvard University, Washington, D. C.

Urcid, Javier, 2005, "La escritura zapoteca: conocimiento, poder y memoria en la antigua Oaxaca", Brandeis University, Massachusetts. Disponible en línea: <http://www.famsi.org/spanish/zapotecwriting/zapotec_text_es.pdf>.

Weitlaner Johnson, Irmgard, 1960, "Un tzotzopaztli antiguo de la región de Tehuacán”, en Anales del Instituto Nacional de Antropología e Historia, t. XI, pp. 75-85.

Weitlaner, Roberto y Gabriel de Cicco, 1998, “La jerarquía de los dioses zapotecos del sur”, en Manuel Ríos Morales (coord.), Los zapotecos de la Sierra Norte de Oaxaca. Antología etnográfica, Instituto Oaxaqueño de las Culturas/Centro de Investigaciones y Estudios Superiores en Antropología Social, Oaxaca, pp. 231-251.

Whitecotton, Joseph W., 2004, Los zapotecos: príncipes, sacerdotes y campesinos, Fondo de Cultura Económica, México.

\section{Entrevistas}

Hermilo Silva, octubre de 2015, San Juan Mixtepec, Oaxaca, México. 